\title{
Extratos de alho e alecrim na indução de faseolina em feijoeiro e fungitoxicidade sobre Colletotrichum lindemuthianum
}

\author{
Garlic and rosemary extracts in the induction of phaseollin in beans and fungitoxicity on \\ Colletotrichum lindemuthianum
}

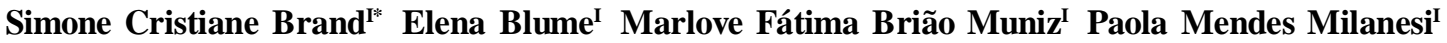 Marina Bergoli Scheren ${ }^{I I}$ Leonardo Magalhães Antonello}

RESUMO

Extratos vegetais podem auxiliar no controle de doenças de plantas, por sua atividade antimicrobiana ou pela ativação de mecanismos de defesa. Neste trabalho, objetivouse avaliar o efeito dos extratos aquosos de alho e alecrim autoclavados e não autoclavados sobre o crescimento micelial de Colletotrichum lindemuthianum, a produção de faseolina em feijoeiro e a severidade de antracnose em campo. $O$ fungo foi incubado em meio de cultura contendo os extratos, e o crescimento foi mensurado por 18 dias. Para avaliação de faseolina, os extratos foram aplicados sobre hipocótilos de feijão, a extração foi feita em etanol e a leitura foi realizada em espectrofotômetro. A severidade da antracnose foi avaliada em plantas de feijão pulverizadas com os extratos e inoculadas com o fungo. Para o extrato de alho, a maior redução (57,6\%) no crescimento micelial foi com a dose de $3,0 \%$ do extrato não autoclavado. Já para o extrato de alecrim, a maior redução $(18,6 \%)$ foi com o extrato autoclavado. A autoclavagem não teve efeito sobre a indução de faseolina. À campo, os extratos não reduziram significativamente a severidade de antracnose. $O$ extrato de alho não autoclavado mostrou-se mais eficiente na redução do crescimento de $\boldsymbol{C}$. lindemuthianum, enquanto que o de alecrim, autoclavado ou não, foi mais efetivo na indução de faseolina.

Palavras-chave: fitoalexinas, antracnose, Allium sativum $L$., Rosmarinus officinalis $L$.

\section{ABSTRACT}

Plant extracts may assist in controlling plants diseases due to its antimicrobial activity and activation of defense mechanisms. This study aimed to evaluate the effect of aqueous extracts of garlic and rosemary, autoclaved or non autoclaved, on the mycelial growth of Colletotrichum lindemuthianum, production of phaseollin by beans and severity of anthracnose in the field. The fungus was incubated in medium containing the extracts and its growth measured for 18 days. For phaseollin evaluation the extracts were applied on bean hypocotyls, the phytoalexin extracted in ethanol and read in spectrophotometer. The severity of anthracnose was evaluated in bean plants sprayed with the extracts and inoculated with the fungus. For the garlic extract, the greater reduction $(57,6 \%)$ in micelial growth was at $3 \%$ in the non autoclaved extract, as for the rosemary extract, the greater reduction $(18,6 \%)$ was in the autoclaved extract. Autoclaving had no effect on the induction of phaseollin. At field conditions, the extracts did not reduce significantly the severity of anthracnose. The non autoclaved garlic extract showed to be more efficient in reducing the mycelial growth of $\boldsymbol{C}$. lindemuthianum, while rosemary, autoclaved or not, proved to be more effective in the induction of phaseollin.

Key words: phytoalexins, anthracnose, Allium sativum L., Rosmarinus officinalis $L$.

\section{INTRODUÇÃO}

A antracnose é uma das mais importantes doenças do feijoeiro, tendo como agente etiológico o fungo Colletotrichum lindemuthianum (Sacc. E Magnus) Scrib. Essa doença compromete o rendimento da cultura e a qualidade do produto final, por isso o uso de produtos químicos tornou-se uma das principais formas de controle. No entanto, torna-se indispensável investigar métodos alternativos para o controle de doenças de plantas que aliem eficiência, menor

'Departamento de Defesa Fitossanitária, Centro de Ciências Rurais (CCR), Universidade Federal de Santa Maria (UFSM), 97105900, Santa Maria, RS, Brasil. E-mail: monebrand@yahoo.com.br. *Autor para correspondência.

IDepartamento de Química, Centro de Ciências Naturais e Exatas (CCNE), UFSM, Santa Maria, RS, Brasil. 
agressividade à saúde humana e ao equilíbrio de ecossistemas (ROMEIRO, 2008), como, por exemplo, os extratos vegetais. Do ponto de vista fitossanitário, os produtos vegetais podem apresentar três atividades principais: antimicrobiana direta, indução de resistência e estímulo do crescimento de plantas (TALAMINI \& STADINIK, 2004). A ação dos fungicidas naturais é ainda influenciada pela termoestabilidade dos compostos presentes nas plantas, que é diretamente dependente da espécie (BALBI-PEÑA et al., 2006).

A ação antimicrobiana sobre fitopatógenos foi verificada sobre o crescimento micelial e a germinação de conídios de Curvularia spp. eAlternaria spp., com a utilização de extrato de bulbos de alho (BARROS et al., 1995). ROZWALKA et al. (2008) observaram inibição de 64,7 e 49,4\% no crescimento micelial de Glomerella cingulata e de $\boldsymbol{C}$. gloeosporioides, respectivamente, quando incubado com extrato aquoso de alecrim autoclavado.

A indução de resistência em plantas envolve a ativação de mecanismos de defesa, como fitoalexinas, enzimas, proteínas relacionadas à patogênese, em resposta ao tratamento com agentes como AcibenzolarS-metil (CAVALCANTI et al., 2006), e extratos vegetais (MAZARO et al., 2008). A fitoalexina mais importante na interação patógeno-planta no feijoeiro é a faseolina, que foi primeiramente detectada por MÜLLER (1958) e, desde então, estudos têm sido conduzidos comprovando sua ação no controle de patógenos, assim como a atividade antifúngica de extratos contendo essa fitoalexina contra $\boldsymbol{C}$. lindemuthianum (DURANGO et al., 2002). Os mesmos autores demonstraram ainda a ligação entre a produção de fitoalexinas em cultivares de feijoeiro e a resistência ou suscetibilidade a patógenos.

Neste trabalho objetivou-se avaliar o efeito dos extratos aquosos de alho (Allium sativum L.) e alecrim (Rosmarinus officinalis L.), com e sem autoclavagem, sobre o crescimento micelial de Colletotrichum lindemuthianum, a produção de faseolina em hipocótilos de feijão e a severidade de antracnose sob condições de campo.

\section{MATERIAL E MÉTODOS}

Preparo dos extratos aquosos: ramos e folhas de alecrim foram coletados no município de São Pedro do Butiá, Rio Grande do Sul (RS), no horário próximo ao pôr do sol, em diferentes épocas do ano. Após, as partes vegetais foram acondicionadas em sacos de jornal e secas em estufa a $40^{\circ} \mathrm{C}$, durante cinco dias. O material seco foi triturado em liquidificador até a obtenção de um pó que foi utilizado no preparo dos extratos, na concentração de $10 \%$ (10g de pó/90mL de água estéril). Para a obtenção do extrato de alho, foram utilizados bulbilhos frescos, adquiridos no comércio, triturados na mesma proporção. O material vegetal permaneceu imerso em água, à temperatura ambiente, por $24 \mathrm{~h}$, para extração dos princípios ativos, sendo coado em tecido de algodão, e os filtrados líquidos resultantes utilizados.

Efeito dos extratos sobre o crescimento micelial de Colletotrichum lindemuthianum: parte dos filtrados foi esterilizada em filtro de celulose $(0,22 \mu \mathrm{m}) \mathrm{e}$ bomba de vácuo, e adicionada ao meio de cultura batata-dextrose-ágar (BDA) autoclavado nas concentrações de 0,$0 ; 0,5 ; 1,0 ; 1,5 ; 2,0 ; 2,5$ e 3,0\%. Outra parte foi adicionada ao meio de cultura BDA nas mesmas concentrações citadas anteriormente, autoclavado a $120^{\circ} \mathrm{C}$, durante $30 \mathrm{~min}$, para avaliar o efeito da autoclavagem sobre a ação dos extratos. Um disco de meio de cultura de $12 \mathrm{~mm}$ de diâmetro, contendo micélio e esporos de $\boldsymbol{C}$. lindemuthianum, foi repicado para placas de Petri contendo meio BDA com as respectivas concentrações dos extratos. As placas foram incubadas a $25^{\circ} \mathrm{C}$ e fotoperíodo de $12 \mathrm{~h}$. As avaliações foram realizadas medindo-se o diâmetro das colônias (média de duas medidas diametralmente opostas) a cada $48 \mathrm{~h}$, durante 18 dias, com paquímetro digital. Para o cálculo da porcentagem de inibição do crescimento micelial, foi utilizada a fórmula proposta por MENTEN et al. (1976).

Efeito dos extratos sobre a produção de faseolina: para essa determinação, foi adaptada a metodologia proposta por DIXON et al. (1983). Sementes de feijão foram esterilizadas em hipoclorito de sódio $1 \%$ por cinco min e lavadas em água destilada esterilizada, semeadas em areia esterilizada e mantidas em câmara climatizada a $24^{\circ} \mathrm{C}$, no escuro. Após sete dias, segmentos de hipocótilos estiolados com $5 \mathrm{~cm}$ foram destacados das plântulas, lavados em água estéril e secos à temperatura ambiente sobre papel filtro estéril. Quatro segmentos de hipocótilo (totalizando $1 \mathrm{~g}$ ) foram colocados em cada placa de Petri contendo papel filtro umedecido com água destilada estéril. Sobre os hipocótilos foi aplicado $1 \mathrm{~mL}$ dos extratos de alho e alecrim, autoclavados e não autoclavados, separadamente, nas concentrações de 0,$0 ; 0,5 ; 1,0 ; 1,5$; 2,$0 ; 2,5$ e 3,0\%. Como testemunha negativa, foi utilizada água mili-Q e, como testemunha positiva, o indutor de defesa vegetal Acibenzolar-S-metil $\left(\right.$ Bion $\left.^{\circledR}\right)$, na concentração de $160 \mathrm{ppm}$, conforme BRAND et al. (2008). As placas foram mantidas a $25^{\circ} \mathrm{C}$, no escuro, por $48 \mathrm{~h}$. Os hipocótilos foram transferidos para tubos de ensaio contendo $10 \mathrm{~mL}$ de etanol, mantidos a $4^{\circ} \mathrm{C}$, por $48 \mathrm{~h}$, e agitados por uma hora para extração da 
faseolina, que foi mensurada indiretamente, a $280 \mathrm{~nm}$ (BAILEY \& BURDEN, 1983).

Avaliação dos extratos vegetais e do indutor comercial sobre a severidade da antracnose sob condições de campo: a cultivar 'Graúna' foi semeada em parcelas de $1,2 \mathrm{~m}^{2}$ com três linhas de plantio e densidade de 10 plantas por metro linear. Os tratamentos para avaliação da indução de resistência foram aplicados quando as plantas atingiram o estádio $\mathrm{V}_{2} / \mathrm{V}_{3}$, no horáriopróximo ao entardecer. Os tratamentos constaram dos extratos de alho e alecrim, autoclavados e não autoclavados, na dose de $3,0 \%$, e do indutor de defesa vegetal Acibenzolar-S-metil, na dose de 160ppm e água destilada estéril. Os tratamentos foram pulverizados nas plantas da fileira central de cada parcela, até o ponto de escorrimento. O inóculo de $\boldsymbol{C}$. lindemuthianum foi produzido em meio de cultura Mathur e, após a esporulação, removido com auxílio de pincel para o preparo da suspensão de esporos. A inoculação foi realizada $48 \mathrm{~h}$ após a aplicação dos tratamentos, com uma suspensão de esporos de 1,2 x $10^{6}$ esporos $\mathrm{mL}^{-1}$. Essa suspensão foi pulverizada sobre as plantas da fileira central de cada parcela, após o pôr do sol, para evitar a desidratação do esporo e do tubo germinativo. A avaliação de severidade da antracnose foi realizada em 10 plantas, aos sete, 14 e 21 dias após a inoculação, com auxílio da escala diagramática proposta por DALLA PRIA et al. (2003).

O delineamento experimental foi o inteiramente casualizado nos ensaios de crescimento micelial e indução de faseolina e, blocos ao acaso no ensaio de severidade da antracnose, com quatro repetições por tratamento. $\mathrm{O}$ experimento de crescimento micelial foi arranjado em fatorial concentrações $\mathrm{x}$ tempos de incubação $\mathrm{x}$ autoclavagem, e o ensaio de indução de faseolina foi arranjado em fatorial concentrações $x$ autoclavagem. Os dados foram submetidos à análise de variância, e as médias foram separadas pelo teste de Tukey, a 5\% de probabilidade, com transformação arco seno $\sqrt{x / 100}$, para as observações expressas em percentagem e, regressão polinomial para os dados de crescimento micelial e indução de faseolina, utilizando-se o Programa SANEST (ZONTA \& MACHADO, 1984).

\section{RESULTADOS E DISCUSSÃO}

Efeito dos extratos sobre o crescimento micelial de Colletotrichum lindemuthianum: houve interação entre os fatores na avaliação do crescimento micelial de $\boldsymbol{C}$. lindemuthianum quando exposto aos extratos de alho e alecrim, optando-se pela apresentação dos resultados das concentrações dos extratos autoclavados e não autoclavados em função do tempo de incubação. $\mathrm{O}$ crescimento do fungo foi linear nos extratos de alho e alecrim autoclavados e exponencial no extrato de alho não autoclavado (Tabela 1), indicando que apenas neste houve um período de adaptação do patógeno ao extrato para, então, ocorrer seu crescimento. O extrato de alho autoclavado afetou o crescimento do fungo especialmente nas concentrações maiores (Figura 1). A dose de 3,0\% proporcionou a maior inibição do crescimento micelial $(12,25 \%)$ após 18 dias de incubação. O extrato de alho não autoclavado acarretou uma quase estagnação no crescimento micelial, nos primeiros três dias de incubação. $\mathrm{O}$ crescimento posterior sugere a adaptação do fungo ao extrato, mas seu potencial no controle de C. lindemuthianum ficou evidente com a redução de $57,60 \%$, na dose de $3,0 \%$, ao final do período de avaliação. O extrato de alho não autoclavado promoveu o menor crescimento micelial, em todas as doses e tempos avaliados, quando comparado ao extrato autoclavado. Esses resultados corroboram os obtidos por RIBEIRO \& BEDENDO (1999), que verificaram redução de até $67,6 \%$ no crescimento de $\boldsymbol{C}$. gloeosporioides pelo extrato de alho não autoclavado. O extrato de alho esterilizado pela filtragem em filtro bacteriológico apresentou atividade antifúngica, contrariamente ao extrato autoclavado, evidenciando que o princípio ativo envolvido é termosensível, como foi também observado neste trabalho.

Efeito deletério da autoclavagem sobre as propriedades inibitórias dos extratos aquosos de arruda, capim-cidreira, erva-de-santa-maria, gengibre, hortelã, hortelã pimenta, mamona, melão-de-são-caetano, seringueira, serralha e trombeteira e para os extratos hidroetanólicos de arruda, beldroega, bucha, café, ervade-santa-maria, eucalipto, fumo, hortelã, hortelã pimenta e melão-de-são-caetano também foram verificados por CELOTO et al. (2008). Por outro lado, segundo os autores, a autoclavagem pode potencializar essas propriedades nos extratos aquosos de bucha, espirradeira, eucalipto, mentrasto e unha-de-vaca e nos extratos hidroetanólicos de capim-cidreira, mamona e unha-de-vaca, sendo a percentagem de inibição do crescimento micelial de C. gloeosporioides maior para os extratos autoclavados.

O crescimento micelial de $\boldsymbol{C}$. lindemuthianum foi afetado pelas dosagens do extrato de alecrim autoclavado. Adose de 2,5\% propiciou maior redução no crescimento do fungo, com inibição de $18,6 \%$ em relação à testemunha (Figura 1), sugerindo que a alta temperatura da autoclavagem pode ter liberado alguns metabólitos tóxicos ao fungo, uma vez que o extrato de alecrim não autoclavado não 
Tabela 1 - Equações e coeficientes de determinação $\left(\mathrm{R}^{2}\right)$ para o crescimento micelial de Colletotrichum lindemuthianum incubado com extrato vegetal autoclavado e não autoclavado de alho (Allium sativum L.) e alecrim (Rosmarinus officinalis L.), para as diferentes concentrações em função do tempo de incubação. Santa Maria, 2008.

\begin{tabular}{|c|c|c|c|c|}
\hline Extrato & & Concentrações (\%) & Equações & $\mathrm{R}^{2}$ \\
\hline \multirow{15}{*}{ Alho } & \multirow{8}{*}{ Autoclavado } & 0,0 & $y=11,79+0,16 x$ & 0,9873 \\
\hline & & 0,5 & $y=10,41+0,16 x$ & 0,9963 \\
\hline & & 1,0 & $y=8,29+0,16 x$ & 0,9944 \\
\hline & & 1,5 & $y=8,84+0,15 x$ & 0,9950 \\
\hline & & 2,0 & $y=7,16+0,14 x$ & 0,9907 \\
\hline & & 2,5 & $y=6,75+0,14 x$ & 0,9894 \\
\hline & & 3,0 & $y=6,07+0,13 x$ & 0,9817 \\
\hline & & & & \\
\hline & \multirow{7}{*}{ Não autoclavado } & 0,0 & $y=8,90+0,205 x-0,0001 x^{2}$ & 0,9935 \\
\hline & & 0,5 & $y=9,82+0,063 x+0,0001 x^{2}$ & 0,9922 \\
\hline & & 1,0 & $y=11,27+0,013 x+0,0001 x^{2}$ & 0,9957 \\
\hline & & 1,5 & $y=12,04-0,007 x+0,0002 x^{2}$ & 0,9981 \\
\hline & & 2,0 & $y=11,87-0,001 x+0,0001 x^{2}$ & 0,9983 \\
\hline & & 2,5 & $y=12,27-0,013 x+0,0001 x^{2}$ & 0,9992 \\
\hline & & 3,0 & $y=12,50-0,021 x+0,0001 x^{2}$ & 0,9965 \\
\hline \multirow{15}{*}{ Alecrim } & \multirow{7}{*}{ Autoclavado } & 0,0 & $y=13,31+0,14 x$ & 0,9922 \\
\hline & & 0,5 & $y=13,51+0,12 x$ & 0,9914 \\
\hline & & 1,0 & $y=13,54+0,12 x$ & 0,9937 \\
\hline & & 1,5 & $y=13,91+0,11 x$ & 0,9893 \\
\hline & & 2,0 & $y=12,39+0,11 x$ & 0,9968 \\
\hline & & 2,5 & $y=11,53+0,11 x$ & 0,9955 \\
\hline & & 3,0 & $y=11,48+0,11 x$ & 0,9983 \\
\hline & \multirow{8}{*}{ Não autoclavado } & & & \\
\hline & & 0,0 & $y=11,79+0,16 x$ & 0,9873 \\
\hline & & 0,5 & $y=11,41+0,14 x$ & 0,9973 \\
\hline & & 1,0 & $y=12,11+0,15 x$ & 0,9972 \\
\hline & & 1,5 & $y=12,75+0,14 x$ & 0,9963 \\
\hline & & 2,0 & $y=12,51+0,15 x$ & 0,9961 \\
\hline & & 2,5 & $y=12,84+0,15 x$ & 0,9944 \\
\hline & & 3,0 & $y=12,56+0,15 x$ & 0,9951 \\
\hline
\end{tabular}

influenciou o crescimento fúngico. ROZWALKA et al. (2008) também relataram efeito inibitório do extrato aquoso de alecrim autoclavado sobre o crescimento micelial de Glomerella cingulata e C. gloeosporioides. Entretanto, ITAKO et al. (2008) verificaram que o extrato bruto aquoso de alecrim, quando autoclavado, não inibiu o crescimento micelial de Alternaria solani. Os resultados deste trabalho e da literatura sugerem que o efeito tóxico do extrato de alecrim autoclavado é dependente do fungo testado. Além disso, pode-se verificar que, para o extrato de alecrim, a autoclavagem potencializou o efeito tóxico sobre o fungo, enquanto que comprometeu a atividade inibitória do extrato de alho, confirmando a ação diferenciada do tratamento térmico sobre os extratos vegetais.

Efeito dos extratos sobre a produção de faseolina: para o acúmulo de faseolina em hipocótilos de feijoeiro tratados com extrato vegetal de alho, houve apenas efeito das concentrações (Figura 2). Todas as doses foram superiores ao tratamento testemunha, não havendo diferença entre estas. No entanto, as doses de 1,0 e 3,0\% do extrato vegetal induziram acúmulo similar de faseolina, com valor de 1,30. No entanto, esse valor foi inferior ao tratamento com o indutor Acibenzolar-S-metil $(1,34)$. BONALDO et al., (2004) observaram que, nas concentrações de 10 e $25 \%$ do extrato aquoso de Eucalyptus citriodora não autoclavado, ocorreu maior indução de deoxiantocianidinas em mesocótilos de sorgo, enquanto que, no extrato autoclavado, a concentração de $15 \%$ induziu maior síntese das fitoalexinas. Os autores afirmam que o tratamento térmico promove modificações no extrato, que podem alterar a produção de deoxiantocianidinas em algumas concentrações, $o$ 


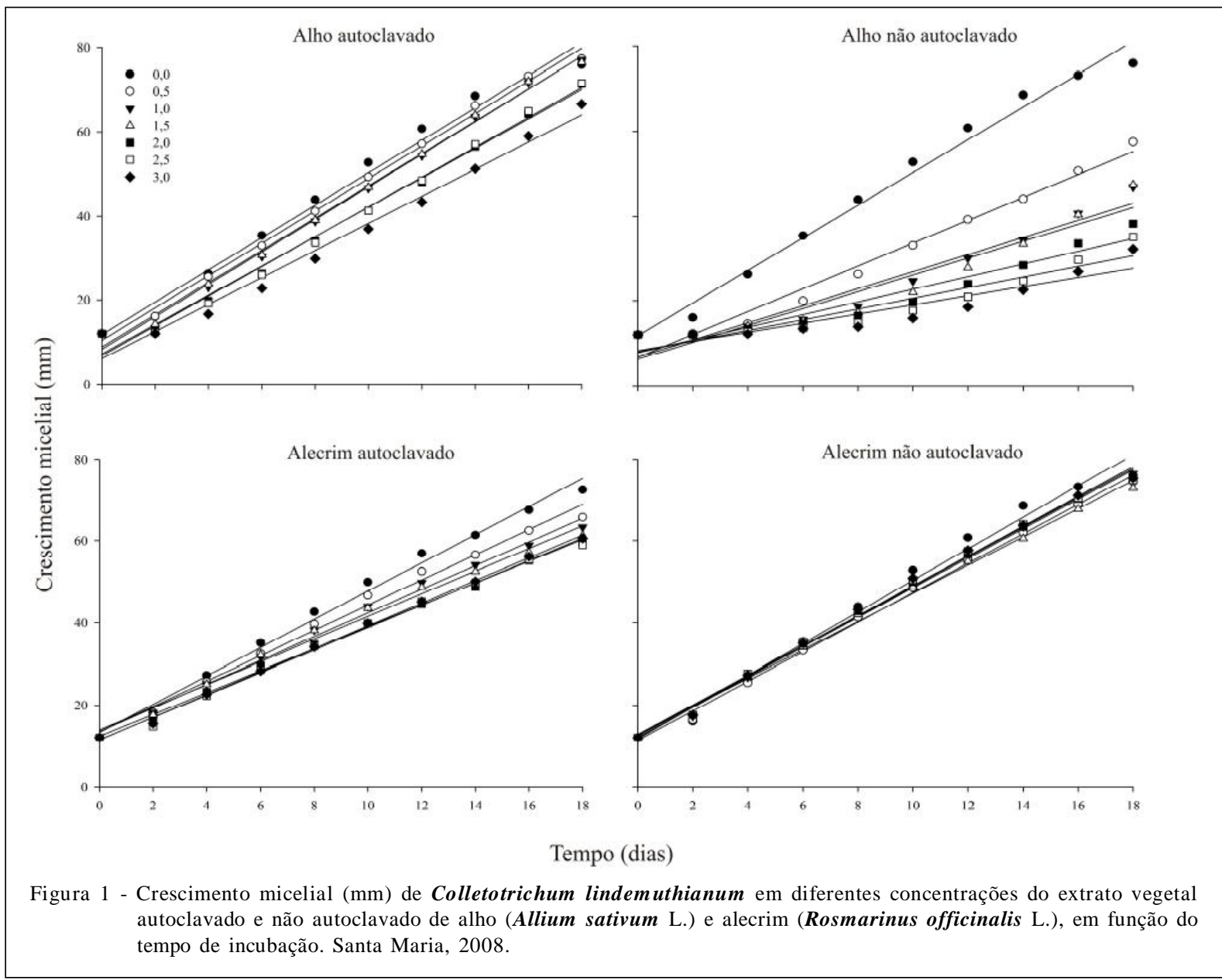

que não foi observado com a faseolina avaliada neste trabalho.

Para a indução de faseolina pelo extrato de alecrim, também não houve efeito da autoclavagem (Figura 2). A maior absorbância $(1,54)$ foi observada na dose de $3,0 \%$, que foi superior ao tratamento com indutor comercial, sendo todas as doses superiores ao tratamento testemunha, porém não havendo diferença estatística entre estas.

Avaliação dos extratos vegetais e do indutor comercial sobre a severidade da antracnose sob condições de campo: na primeira avaliação, aos sete dias, foram observadas apenas pequenas lesões em poucas plantas, em virtude de as condições ambientais não terem sido favoráveis à ocorrência da doença. $\mathrm{Na}$ segunda e na terceira avaliação (dados não mostrados), não foi verificada diferença entre os tratamentos, possivelmente, devido ao coeficiente de variação elevado. Ainda assim, observou-se uma redução da severidade pelo uso dos extratos de alho não autoclavado e alecrim autoclavado, equivalente ao indutor Acibenzolar-S-metil, corrobando os resultados in vitro, em que esses extratos mostraram maior ação antimicrobiana e na indução de faseolina, respectivamente. NOWACKI (2005) observou que o tratamento com decoctos do extrato de alho inibiu em $60 \%$ a incidência de galhas das crucíferas em couve chinesa e proporcionou menores níveis de severidade. No mesmo estudo, o tratamento com decoctos do extrato de alecrim apresentou incidência de galhas em $100 \%$ das plantas inoculadas e níveis médios de severidade.

\section{CONCLUSÃO}

O extrato de alho não autoclavado na dose de 3,0\% é mais eficiente na redução do crescimento micelial de Colletotrichum lindemuthianum in vitro, enquanto o extrato de alecrim na dose de $3,0 \%$, com ou sem autoclavagem, é mais efetivo na indução de faseolina. Os extratos de alho e alecrim não reduzem significativamente a severidade da antracnose em feijoeiro, nas condições estudadas.

Ciência Rural, v.40, n.9, set, 2010. 


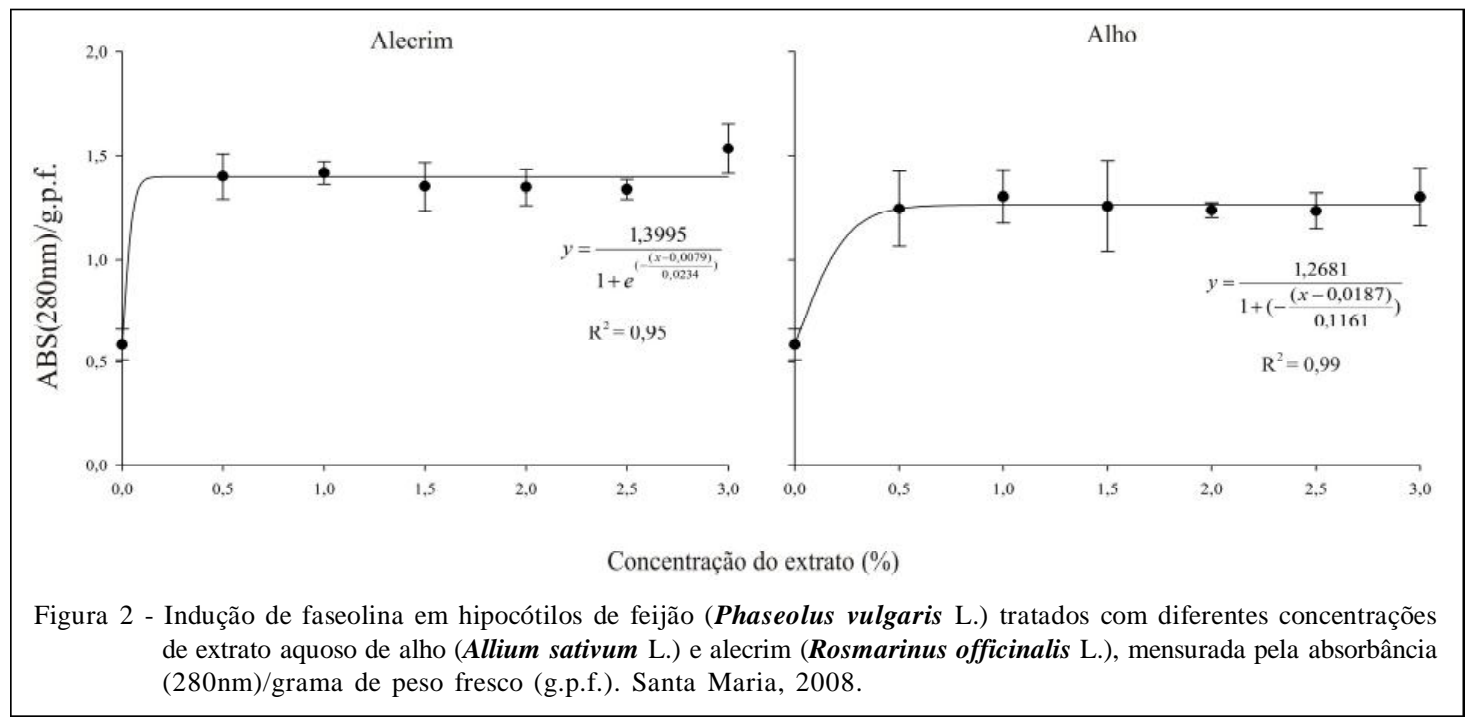

\section{AGRADECIMENTO}

À Fundação de Apoio à Pesquisa do Estado do Rio Grande do Sul (FAPERGS), pela concessão de bolsa ao pesquisador Simone Brand.

\section{REFERÊNCIAS}

BAILEY, J.A.; BURDEN, R.S. Biochemical changes and phytoalexin accumulation in Phaseolus vulgaris following cellular browning caused by tobacco necrosis virus. Physiological Plant Pathology, London, v.3, n.1, p.171177, 1983.

BALBI-PEÑA, M.I. et al. Controle de Alternaria solani em tomateiro por extratos de Curcuma longa e curcumina - I. avaliação in vitro. Fitopatologia Brasileira, Brasília, v.31, n.3, p.310-314, 2006. Disponível em: <http://www.scielo.br/scielo.php?pid=S010041582006000400012\&script=sci_arttext $>$. Acesso em: 24 ago. 2008. doi: 10.1590/S0100-41582006000400012.

BARROS, S.T. et al. Efeito do extrato de alho (Allium sativum) sobre o crescimento micelial e germinação de conídios de Curvularia spp. e Alternaria sp. Summa Phytopathologica, Botucatu, v.21, n.2, p.168-170, 1995.

BONALDO, S.M. et al. Fungitoxidade, atividade elicitora de fitoalexinas e proteção de pepino contra Colletotrichum lagenarium, pelo extrato aquoso de Eucalyptus citriodora. Fitopatologia Brasileira, Brasília, v.29, n.2, p.128-134, 2004. Disponível em: $<$ http://www.scielo.br/scielo.php?script=sci_arttext\&pid=S0100$41582004000200002 \& \operatorname{lng}=\mathrm{pt} \& \mathrm{nrm}=\mathrm{iso} \& \mathrm{t} \operatorname{lng}=\mathrm{pt}>$. Acesso em: 10 nov. 2008. doi: 10.1590/S0100-41582004000200002.

BRAND, S.C. et al. Acibenzolar-S-Metil na indução de fitoalexinas em Phaseolus vulgaris. In: CONGRESSO NACIONAL DE PESQUISA DE FEIJÃO, 9., 2008, Campinas, SP. Anais... Campinas: Congresso Nacional de Pesquisa de Feijão, 2008. p.1028-1031.

CAVALCANTI, F.R. et al. Acibenzolar-S-metil e Ecolife ${ }^{\circledR}$ na indução de respostas de defesa do tomateiro contra a mancha bacteriana (Xanthomonas vesicatoria). Fitopatologia Brasileira, Brasília, v.31, n.4, p.372-380, 2006. Disponível em: <http:// www.scielo.br/scielo.php? script $=$ sci_arttext $\&$ pid $=S 0100$ $41582006000400007 \& \operatorname{lng}=\mathrm{pt} \& \mathrm{nrm}=\mathrm{iso} \& \mathrm{t} \operatorname{lng}=\mathrm{pt}>$. Acesso em: 24 set. 2008. doi: 10.1590/S0100-41582006000400007.

CELOTO, M.I.B. et al. Atividade antifúngica de extratos de plantas a Colletotrichum gloeosporioides. Acta Scientiarum Agronomy, v.30, n.1, p.1-5, 2008. Disponível em: <http:// periodicos.uem.br/ojs/index.php/ActaSciAgron/article/ viewArticle/1104>. Acesso em: 15 set. 2008. doi: 10.4025/ actasciagron.v30i1.1104.

DALLA PRIA, M. et al. Quantificação de componentes monocíclicos da antracnose do feijoeiro. Fitopatologia Brasileira, Brasília, v.28, n.4, p.401-407, 2003. Disponível em: $<$ http://www.scielo.br/scielo.php?script=sci_arttext\&pid=S0100$41582003000400008 \& \operatorname{lng}=\mathrm{pt} \& \mathrm{nrm}=\mathrm{iso} \& \mathrm{t} \operatorname{lng}=\mathrm{pt}>$. Acesso em: 27 out. 2008. doi: 10.1590/S0100-41582003000400008.

DIXON, R.A. et al. Phytoalexin indution in french bean: intercellular transmission of elicitation in cell suspension cultures and hypocotyl sections of Phaseolus vulgaris. Plant Physiology, Waterbury, v.71, n.2, p.251-256, 1983.

DURANGO, D. et al. Phytoalexin accumulation in Colombian bean varieties and aminosugars as elicitors. Molecules, Basel, v.7, n.11, p.817-832, 2002. Disponível em: <http:// www.mdpi.com/1420-3049/7/11/817/>. Acesso em: 13 ago. 2008. doi:10.3390/71100817.

ITAKO, A.T. et al. Atividade antifúngica e proteção do tomateiro por extratos de plantas medicinais. Tropical Plant Pathology, Brasília, v.33, n.3, p.241-244, 2008. Disponível em: <http:// www.scielo.br/scielo.php? script $=$ sci_arttext $\&$ pid $=$ S1982 $56762008000300011 \& \operatorname{lng}=\mathrm{pt} \& n r m=i s o \& t \operatorname{lng}=\mathrm{pt}>$. Acesso em: 25 set. 2008 . doi: 10.1590/S1982-56762008000300011.

MAZARO, S.M. et al. Indução de fitoalexinas em cotilédones de soja em resposta a derivados de folhas de Pitangueira. Ciência Rural, Santa Maria, v.38, n.7, p.1824-1829, 2008. Disponível em: <http:/ $/$ www.scielo.br/scielo.php?script=sci_arttext\&pid=S0103- 
$84782008000700004 \& \operatorname{lng}=\mathrm{pt} \& \mathrm{nrm}=\mathrm{iso} \& \mathrm{tlng}=\mathrm{pt}>$. Acesso em: 30 nov. 2008. doi: 10.1590/S0103-84782008000700004.

MENTEN, J.O.M. et al. Efeito de alguns fungicidas no crescimento micelial de Macrophomina phaseolina (Tass.) Goid. "in vitro". Fitopatologia Brasileira, Brasília, v.1, n.2, p.5766,1976

MÜLLER, K.O. Studies on phytoalexins. I. The formation and the immunological significance of phytoalexin produced by Phaseolus vulgaris in response to infection with Sclerotinia fructicola and Phytophthora infestans. Australian Journal of Biological Sciences, East Melbourne, v.11, n.1, p.275$300,1958$.

NOWACKI, J.C. Efeitos de extratos vegetais no controle da galha das crucíferas em condições de casa de vegetação. 2005. 54f. Dissertação (Mestrado em Agronomia) - Curso de Pós-graduação em Agronomia, Universidade Federal do Paraná, PR.

RIBEIRO, L.F.; BEDENDO, I.P. Efeito inibitório de extratos vegetais sobre Colletotrichum gloeosporioides - agente causal da podridão de frutos de mamoeiro. Scientia Agricola, Piracicaba, v.56, n.4, p.1267-1271, 1999. Disponível em: <http://
www.scielo.br/scielo.php?script=sci_arttext\&pid=S0103$90161999000500031 \& \operatorname{lng}=\mathrm{pt} \& \mathrm{nrm}=\mathrm{iso} \& \operatorname{tng}=\mathrm{pt}>$. Acesso em: 25 set. 2008. doi: 10.1590/S0103-90161999000500031.

ROMEIRO, R.S. Indução de resistência em plantas a patógenos. In: PASCHOLATI, S.F. et al. (Eds). Interação plantapatógeno: fisiologia, bioquímica e biologia molecular. Piracicaba: FEALQ, 2008. Cap.13, p.411-431.

ROZWALKA, L.C. et al. Extratos, decoctos e óleos essenciais de plantas medicinais e aromáticas na inibição de Glomerella cingulata e Colletotrichum gloeosporioides de frutos de goiaba. Ciência Rural, Santa Maria, v.38, n.2, p.301-307, 2008. Disponível em: <http://www.scielo.br/scielo.php?script=sci_arttext\&pid=S0103$84782008000200001 \& \operatorname{lng}=\mathrm{pt} \& \mathrm{nrm}=\mathrm{iso} \& \mathrm{t} \operatorname{lng}=\mathrm{pt}>$. Acesso em: 12 ago. 2008. doi: 10.1590/S0103-84782008000200001.

TALAMINI, V.; STADINIK, M.J. Extratos vegetais e de algas no controle de doenças de plantas. In: TALAMINI, V.; STADINIK, M.J. Manejo ecológico de doenças de plantas. Florianópolis: CCA/UFSC, 2004. p.45-62.

ZONTA, E.P.; MACHADO, A.A. Sistema de análise estatística para microcomputadores - SANEST. Pelotas: UFPel, 1984. 75p. 